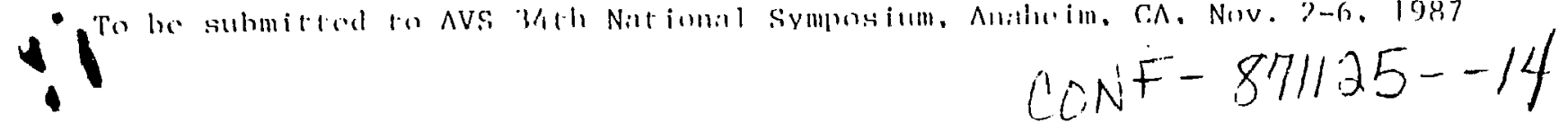

\title{
DEPTH OF ORIGIN OF SPUTTERED ATOMS: EXPERIMENTAL AND THEORETICAL STUDY OF $\mathrm{Cu} / \mathrm{Ru}(0001)^{*}$
}

\author{
J.W. Burnett, † J.P. Biersack, †† D.M. Gruen, B. Jørgensen, \\ A.R. Krauss, M.J. Pellin, E.L. Schweitzer, J.T. Yates, Jr., † and C.E. Young \\ Malterials Science and Chemistry Divisions \\ Argonne National Liboratory, Argonne, IL 60439
}

The depth of origin of sputtered atoms is a subject of considerable interest. The surface sensitivity of analytical techniques such as Secondary Ion Mass Spectrometry (SIMS) and Surface Analysis by Resonance Ionization of Sputtered Atoms (SARISA), and the sputtering properties of strongly segregating alloy systems, are critically dependent on the sputtering depth of origin. A significant discrepancy exists between the predictions of the Sigmund theory and computer sputtering models; in general, the computer models predict a much shallower depth of origin. The existing experimental evidence suggests that most of the sputtered atoms originate in the topmost atomic layer, but until recently, the results have not been definitive. We have experimentally determined the depth of origin of atoms sputtered from surfaces consisting of $\mathrm{Cu}$ films of less than two monlayers on a $\mathrm{Ru}(0001)$ substrate. The $\mathrm{Cu} / \mathrm{Ru}$ target was statically sputtered using $3.6 \mathrm{keV} \mathrm{Ar}{ }^{+}$. The sputtered neutrals were non-resonantly laser ionized and detected using SARISA. The $\mathrm{Cu} / \mathrm{Ru}$ sputtering yield ratio and the suppression of the Ru sputtering yield were determined for various $\mathrm{Cu}$ coverages. The results indicate that the majority of the sputtered atoms originate in the topmost atomic layer. The $\mathrm{Cu} / \mathrm{Ru}$ system is also modeled using a modified TRansport of Ions in Matter (TRIM) code. It was found that TRIM C does not correctly treat the first atomic layer, resulting in a serious underestimate of the number of sputtered atoms which originate in this layer. The corrected version adequately describes the results, predicting that for the experimental conditions roughly two-thirds of the sputtered atoms originate in the first atomic layer. These results are significartly greater than the Sigmund theory estimate of $>40 \%$.

\footnotetext{
*Work st:pported by the U.S. Dept. of Energy, BES Materials Sciences, under Contract No. W-31-109.ENG-38 and by a grant of computer time at the Energy Research Cray X-MP at the MFE Computing Center, Livermore, CA.

†Pittsburgh Surface Science Center, University of Pittsburgh, Pittsburgh, PA USA.

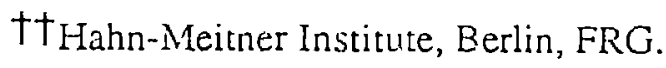

CONF-871125--14

DE88 002848 


\section{DISCLAIMER}

This report was prepared as an account of work sponsored by an agency of the United States Government. Neither the United States Government nor any agency thereof, nor any of their employees, makes any warranty, express or implied, or assumes any legal liability or responsibility for the accuracy, completeness, or usefulness of any information, apparatus, product, or process disclosed, or represents that its use would not infringe privately owned rights. Refe:ence herein to any specific commercial product, process, or service by trade name, trademark, manufacturer, or otherwise does not necessarily constitute or imply its endorsement, recommendation, or favoring by the United States Government or any agency thereof. The views and opinions of authors expressed herein do not necessarily state or reflect those of the United States Government or any agency thereof. 


\section{Introduction}

Energetic ion bombardment of a target surface can, following a series of atomic collisions, lead to the ejection of target atoms. A fundamental understanding of this process, known as sputtering, is technologically important to a wide variety of industries. In the semiconductor industry, for instance, sputtering is used to create structured device surfaces both by deposition of sputtered atoms (sputter-deposition) and by removal of surface atoms (plasma etching). For magnetic confinement fusion, the sputtering process due to plasma-wall interactions represents the start of a parasitic energy loss mechanism which could unfavorably alter the input energy required to reach the scientific breakeven point. Furthermore, analytical instruments which utilize ion beam probes to detect sputtered atoms yield more information if the sampling depth of sputtering is well known.

Despite the importance of sputtering, a fundamental understanding of many aspects of this process has resiained lacking. This is due both to the complexity of a sputtering event and to the experimental difficulties involved in its study. The depth of origin $\left(D_{0}\right)$ of sputtered species is one such aspect which is currently the object of considerable debate. Theoretical efforts to understand the depth of origin of sputtered atoms are summarized in Table 1. Sigmund's theory, ${ }^{1-3}$ based on an isotropic binary collision approximation, is analytic and defines two types of depths or origin. The first, calleu the characteristic $D_{0}$, is the depth from which $1 / 3$ of all sputtered species are ejected. Implicit in this model is the assertion that the sputtering yield decreases exponentially with depth. While the $D_{0}$ varies with target density this model typically predicts that $40 \%$ of all sputtered species originate in the surface atomic layer. A second definition of $D_{0}$ is the sample thickness which gives rise to sputtering. While this number is target and primary ion dependent, for $5 \mathrm{keV} \mathrm{Ar}^{+}$ normally incident on $\mathrm{Cu}$, the depth contributing to the sputter yield is roughly $20 \AA$.

A second type of theoretical investigation is represented by computer simulations of the sputtering process. Two such efforts are represented by the Monte Carlo collision codes TRIM 4 and MARLOWE. 5,6 TRIM assumes an amorphous target and MARLOWE 
can utilize single crystal targets. A third computer code allows for multiple interactions by calculating multiple collisions in a crystal lattice. 7,8 As illustrated in Table 1, each of these calculations finds that greater than $75 \%$ of all sputtered atoms originate in the first atomic layer for a wide range of target, primary ion combinations.

Dumke and Tombrello 9 studied the sputtering of the liquid indium-gallium eutectic alloy using a 15 and $25 \mathrm{keV} \mathrm{Ar}{ }^{+}$beam. Due to surface segregation, the concentration of indium at the surface was found to be greater than $94 \%$ as determined by Ion Scattering Spectroscopy (ISS) and Auger studies. The bulk indium concentration is only $16.5 \%$ in the eutectic alloy. By assuming that the second layer concentration was that of the bulk alloy and using a plate to collect the sputtered species, the experimenters determined that more than $85 \%$ of the sputtered species originated in the first layer for $15 \mathrm{keV}$ ion bombardment. For $25 \mathrm{keV}$ ion bombardment, the first layer contributed $70 \%$ of the sputtered atoms. If the assumption that only the very first layer concentration is affected by the surface segregation is incorrect, the estimates of the first layer contributions to the sputtering yield are also incorrect.

Definitive experimental studies of $D_{O}$ are virtually nonexistent. The difficulty arises in producing a well-characterized layered structure and then quantitatively measuring the sputtering yields of each layer component with a primary ion dose low enough to avoid residual damage effects.

In this publication, Surface Analysis by Resonance Ionization of Sputtered Atoms (SARISA) ${ }^{10-13}$ is used to investigate $D_{0}$ for solid surfaces. The method of investigation is straightforward. First, a well-characterized Cu overlayer is deposited upon a clean single crystal Ru surface (0001). Then SARISA is used in a nonresonant ionization mode to simultaneously determine the sputtering yield of both $\mathrm{Cu}$ and $\mathrm{Ru}, \mathrm{S}_{\mathrm{Cu}}$ and $\mathrm{SRu}$. By quantitatively detecting $\mathrm{S}_{\mathrm{Cu}}$ and $\mathrm{S}_{\mathrm{Ru}}$ as a function of $\mathrm{Cu}$ coverage, the suppression of the Ru yield and the ratio of sputtered $\mathrm{Cu}$ to $\mathrm{Ru}$ can be determined. Subsequent experiments have determined that the secondary ion yields for this system represent a negligible fraction 
of the sputtered flux. Because of the high detection efficiency of the SARISA technique, these measurements are made in a static mode, i.e., on average over the course of measurement no primary ion strikes a previously impacted area.

There are several important reasons that the extensively studied $\mathrm{Cu} / \mathrm{Ru}(0001)$ system has been chosen for this work. Deposition of $\mathrm{Cu}$ on the $\mathrm{Ru}(0001)$ surface has been demonstrated to result in layer by layer $\mathrm{Cu}$ film growth up to 2 monolayer coverage. 15-20 Furthermore, this growth is essentially pinhole free 20 with the first layer being more strongly bound to the surface than the second $\mathrm{Cu}$ layer. $15-20$ LEED patterns as a function of $\mathrm{Cu}$ coverage demonstrate pseudomorphic growth for up to 2 monolayers of $\mathrm{Cu}$ coverage. ${ }^{16-19}$

In this publication, we will briefly describe Auger Electron Spectroscopy (AES) of this surface which confirms the previous work and allows unequivocal establishment of the absolute Cu coverage. This is extremely important since a careful measure of the $D_{0}$ for sputtered atoms on this system hinges on precise determination of the $\mathrm{Cu}$ coverage for each sample.

In conjunction with the experiments, model calculations have been made using a corrected version of the TRIM Monte Carlo code, based on the Biersack-Ziegler universal potential. The basic approach has been described elsewhere 24 , but the correction used in the present work will be briefly described. TRIM treats the electronic and nuclear losses independently. The electronic losses are treated as a continuous process beginning when the primary ion crosses the surface in accord with LSS theory. The nuclear losses occur only when a collision occurs between the cascade atoms and the stationary lattice atoms. It is assumed by TRIM that a cascade atom must travel at least a distance $P_{\max }$ between consecutive nuclear collisions, where $P_{\max }$ is proportional to the average interatomic spacing. For the first collision however, the distance is measured from the surface of the material. Since $P_{\max }$ is typically 1-2 $\AA$, a significant fraction of the nuclear stopping in the first atomic layer is ignored, and the sputtering yield associated with atoms originating 
in the first atomic layer is underestimated. This unphysical result is evident in depth of origin calculations using TRIM 24 in which no sputtered atoms were found to originate in the first atomic layer. Tnis artifact is not present in an earlier version of TRIM25,26 which treats the electronic stopping as a discrete process and therefore defines the surface in a consistent manner. As a simple cure, $P_{\max }$ has been calculated and the first atomic layer has been increased in thickness by $P_{\max }$. All of the nuclear collision events are therefore correctly counted, although there is an increased electronic energy loss corresponding to the transit through the first 1-2 $\AA$ of material. Consequently, the available kinetic energy is slightly reduced when the primary ion reaches the "true surface". An estimate of the effect of this approximation may be made from Fig. 1, which shows the calculated first and second layer depth of origin for $\mathrm{Ar}^{+}$bombardment of $\mathrm{Ru}$ as a function of primary ion kinetic energy. For low energies, the depth of origin increases rapidly with kinetic energy, but for energies in excess of $1-2 \mathrm{keV}$, the depth of origin is nearly independent of the primary energy. Consequently, the error introduced by artificially redefining the surface is only expected to be significant at very low impact energies and is not expected to affect the application to the current experimental conditions.

\section{Experimental}

The SARISA apparatus consists of four parts: a UHV chamber, two pulsed lasers, a pulsed ion source, and an ion detector. The UHV chamber is equipped with LEED (VG Corporation), a single pass cylindrical mirror electron energy analyzer for Auger spectroscopy (Physical Electronics Corporation Model 150), and a quadrupole residual gas analyzer (UTI model 100C). The chamber is routinely pumped into the low $10^{-10}$ torr range by a $200 \mathrm{l} / \mathrm{s}$ ion pump (Ultek model 207-0232) assisted by a titanium sublimator. During ion bombardment the chamber pressure rises into the low $10^{-9}$ tor region, with argon as the primary residual gas. The laser used for non-resonant ionization is a $\mathrm{XeCl}$ excimer laser (Lambda Physik, EMG $201 \mathrm{MSC}$ ) which provides a $10 \mathrm{nsec}, 300$ 
mj pulse at $308 \mathrm{~nm}(4.03 \mathrm{eV})$. With ionization potentials of $7.72 \mathrm{eV}$ and $7.36 \mathrm{eV}$ for copper and ruthenium respectively, both ionizations require two photons.

A diagram of the SARISA apparatus is shown in figure 2. A complete description of the operation of the SARISA apparatus is given in references $10-13$. The $5 \mathrm{keV}$ argon ion beam is produced by an ion source (Colutron Corporation). The beam is apertured to 10 namps and then chopped into $500 \mathrm{nsec}$ pulses. The beam diameter at the target was approximately 30 microns and each pulse contains approximately $3.1 \times 10^{4}$ argon ions. The laser pulse ionizes the sputtered neutrals above the target surface. An Energy and Angular Refocussing-Time of Flight (EAR - TOF) mass spectrometer is used to separate and detect the different photo-ion species.

The ruthenium single crystal (Metal Crystals and Oxides, LTD) was oriented and cut perpendicular to the (0001) axis. The (0001) face was oriented to $\pm 1^{\circ}$ and polished to a mirror finish. A commercially available heater button (Spectra-Mat Corp.) was used to heat the sample to temperanres of up to $1500 \mathrm{~K}$. Good thermal contact was made between the heater button and the crystal by bonding the crystal to the heater with a high temperature alumina based adhesive (Cotronics Corporation).

Auger spectroscopy was used to monitor the cleanliness of the ruthenium surface. Cleaning was achieved by $\mathrm{Ar}^{+}$bombardment followed by repeated cycles of heating the crystal to $1500 \mathrm{~K}$ in a $5 \times 10^{-7}$ torr oxygen background and then heating the crystal to $1500 \mathrm{~K}$ in vacuum. $14,19,20$ The Auger spectrum showed no traces of sulphur or oxygen. The carbon Auger feature near $274 \mathrm{eV}$ is of nearly the same energy as the ruthenium structure near $274 \mathrm{eV}$. A carbon free surface is assumed if the differentiated negative to positive peak ratio of the ruthenium $274 \mathrm{eV}$ auger feature is $1.20 .14,19,20$

Copper was deposited onto the ruthenium by evaporation. Marz grade copper wire was wrapped around a tungsten filament and the tungsten filament was mounted on outgassing loops. By controlling the voltage across the deposition filament, reproducible copper evaporation rates can be achieved. 14,19,20 The deposition filament was outgassed 
for several hours before use; Auger revealed no contaminants in the deposited copper layer, except for chlorine. The chlorine was removed by annealing the sample at $1100 \mathrm{~K}$ for about five minutes.

The calibration of the copper coverage was carried out in a unique fashion. Copper was slowly and in a controlled manner evaporated from the ruthenium surface. The target was positioned in front of the Auger spectrometer and the differentiated peak to peak intensities of the Copper $920 \mathrm{eV}$ and $60 \mathrm{eV}$ and the ruthenium $274 \mathrm{eV}$ were recorded for decreasing copper coverages. A $3 \mathrm{keV}, 5$ microamp electron beam was used and the modulation voltage was $2 \mathrm{eV}$. Neither the sample position nor the Auger parameters were changed for the course of the experiment. This allowed the absolute copper and ruthenium Auger intensities to be compared directly. As expected, a plot of the copper vs. the ruthenium Auger intensities was linear within copper overlayers and showed sharp breaks at the completion of one monolayer. 15-18,21,22 Furthermore, the increased binding energy of the first copper layer relative to that of the second layer was expected to show a dramatic change in the copper desorption rate. With sufficient control of the desorption, the change in the Auger intensities of copper and ruthenium with heating time showed a dramatic change when only one monolayer of copper remained.

\section{Results and Conclusions}

The results of the sputtering experiment are shown in figure 3. Three measurements of the $\mathrm{Cu} / \mathrm{Ru}$ Sputter yield ratio, $\mathrm{SCu}_{\mathrm{S}} / \mathrm{S}_{\mathrm{R}}$, for three different copper coverages were completed. As expected, the experimental results show that as more copper is deposited, $\mathrm{S}_{\mathrm{Cu}} / \mathrm{S}_{\mathrm{Ru}}$ increases. At one monolayer of copper coverage, $\mathrm{S}_{\mathrm{Cu}} / \mathrm{S}_{\mathrm{Ru}}$ is 3.2. This is significantly larger than the ratio of the elemental $\mathrm{Cu}$ sputtering yield,

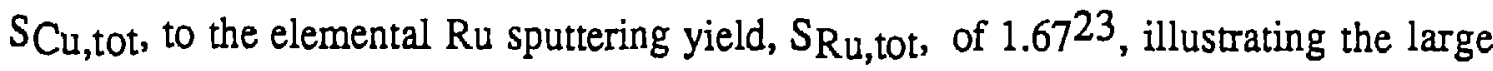
surface contribution to sputtering.

The experimental value of $\mathrm{S}_{\mathrm{Cu}} / \mathrm{S}_{\mathrm{Ru}}$ may be used to estimate the first layer contribution to sputtering, ie., the suppression of the Ru sputtering yield. Assuming that 
the fraction of the total elemental sputtering yield originating in the topmost layer is the same for both $\mathrm{Cu}$ and $\mathrm{Ru}$ and that the $\mathrm{Cu}$ and $\mathrm{Ru}$ atoms sputter from the $\mathrm{Cu} / \mathrm{Ru}$ system as if from their respective bulk metals, then:

$$
\mathrm{S}_{\mathrm{Cu}} / \mathrm{S}_{\mathrm{Ru}}=\mathrm{X} \mathrm{S}_{\mathrm{Cu}, \mathrm{tot}} /(1-\mathrm{X}) \mathrm{S}_{\mathrm{Ru}, \mathrm{tot}}
$$

where $\mathrm{X}$ is the fraction of the total sputtering originating in the first layer, $(1-\mathrm{X})$ is the fraction arising from below the first layer, and $S_{C u}$, tot and $S_{R u, t o t}$ are the elemental sputter yields for $\mathrm{Cu}$ and $\mathrm{Ru}$. For $3.6 \mathrm{keV} \mathrm{Ar}^{+}$bombardment, $\mathrm{S}_{\mathrm{Cu}}$, tot and $\mathrm{S}_{\mathrm{Ru}}$, tot are 4.5 and 2.7, respectively .23 Substituting the experimental value of 3.2 for $\mathrm{SCu}_{\mathrm{Cu}} / \mathrm{S}_{\mathrm{Ru}}$ in to the equation, $\mathrm{X}$ is calculated to be .66 , ie., two thirds of the sputtering yield is from the first layer.

In order to assess this value let us examine the critical assuraptions. Similar first layer contributions to sputtering for $\mathrm{Cu}$ and $\mathrm{Ru}$ elemental targets are supported by TRIM calculations which show virtually identical depth of origin distributions for the sputtering of elemental $\mathrm{Cu}$ and $\mathrm{Ru} ; 79 \pm 4 \%$ of the sputtering is from the first layer for both $\mathrm{Cu}$ and $\mathrm{Ru}$. The assumption that $\mathrm{Cu}$ and $\mathrm{Ru}$ sputter with yields per layer similar to their bulk metals underestimates $\mathrm{X}$ since $\mathrm{Cu}$ is less effective in shielding the $\mathrm{Ru}$ substrate than is a layer of $\mathrm{Ru}$. This is due to the mass mismatch between $\mathrm{Cu}$ and $\mathrm{Ru}$, the lower binding energy of $\mathrm{Cu}$ to $\mathrm{Ru}$ than of $\mathrm{Ru}$ to $\mathrm{Ru}$, and the decreased density of the Cu overlayer. TRIM calculations support this assertion. The suppression of the Ru sputter yield by one ML of $\mathrm{Cu}$, calculated by TRIM, is $70 \pm 4 \%$, while the calculated fraction of the total sputtering yield from the first layer of pure $\mathrm{Ru}$ is $79 \pm 4 \%$. For these reasons, the $\mathrm{Cu} / \mathrm{Ru}$ measurements are expected to be an underestimate of the first layer contribution to sputtering when compared with elemental targets.

Results of the TRIM computer calcuiations are also shown in figlre 3. TRIM calculations of $\mathrm{SCu}_{\mathrm{C}} / \mathrm{S}_{\mathrm{Ru}}$ increase with increasing Cu coverage, although more rapidly than do the experimental values. At one $\mathrm{ML}$ of $\mathrm{Cu}$ coverage, TRIM predicts a $\mathrm{S}_{\mathrm{Cu}} / \mathrm{S}_{\mathrm{Ru}}$ of 4.5 , a value somewhat higher than the experimental value of 3.2. TRIM predicts the 
suppression of the Ru sputtering yield due to one $\mathrm{Cu}$ monolayer to be $70 \%$, in excellent agreement with the experimental estimate.

For the first time, definitive measurements on the depth of origin have been made. The studies were conducted on carefully characterized $\mathrm{Cu}$ covered $\mathrm{Ru}$ single crystals. The experimental results show that for $3.6 \mathrm{keV} \mathrm{Ar}{ }^{+}$bombardment of the $\mathrm{Cu} / \mathrm{Ru}$ system, sputtering is mostly a first layer phenomenon. Because the Cu overlayer is less effective in shielding the Ru substrate than is a layer of $\mathrm{Ru}$, the first layer contribution to sputtering for the $\mathrm{Cu} / \mathrm{Ru}$ system is expected to be less than that of pure $\mathrm{Ru}$. For similar reasons, the depth of origin of sputtered atoms from many elemental targets may be at least as shallow as the $\mathrm{Cu} / \mathrm{Ru}$ experiment indicates. Sigmund's analytical calculation of $\mathrm{X}=0.4^{1-3}$ is less than the experimental value of two-thirds. The TRIM results, showing much better although not exact agreement with the experiment, calculate the slightly higher value of $70 \%$. 
TABLE I. VARIOUS ESTIMATES OF THE DEPTH OF ORIGIN

SOURCE DEFINITION

SPUTTERED

FRACTION ARISING

FROM FIRST LAYER

Sigmund (theory) ${ }^{1-3}$

Characterisic depth of Origin

$<40 \%$

$$
\begin{aligned}
& D_{0}=3 /\left(4 N C_{0}\right) \\
& N=\text { Target Number Density } \\
& C_{0}=\text { constant }(1.808)
\end{aligned}
$$

Sigmund (theory) ${ }^{1-3}$

Total thickness contributing to

N/A

Sputtering is $25-50 \%$ of the

Primary Ion Penetration Depth

TRIM 4

MARLOWE 5,6

Binary Collision, Monte Carlo

$>75 \%$

Computer Calculation

MULTIPLE

INTERACTION

SIMULATION 7,8

In-Ga Liquid

Eutectic

(Experimental) ${ }^{9}$ 


\section{References}

1. P. Sigmund, Phys. Rev. 184, 383(1969); 187 768(1969).

2. G. Falcone and P. Sigmund, Appl. Phys. 25, 307(1981).

3. P. Sigmund, Sputtering by Particle Bombardment II, (ed., R. Behrisch) Springer Verlag, Berlin, Heidelberg 1981.

4. J. P Biersack and W. Eckstein, Appl. Phys. A34, 73(1984).

5. M. T. Robinson, J. Appl. Phys. 54, 2650(1983).

6. M. Rosen, G. P. Mueller, and W. A. Fraser, Nucl. Instru. Meth. 209/210, 63(1983).

7. D. E. Harrison, Jr., Rad. Eff. 70, 1(1983).

8. D. E. Harrison, P. W. Kelly, B. J. Garrison, and N. Winograd, Surf. Sci. 76. 311(1978).

9. M. F. Dumke, T. A. Tombrello, R. A. Weller, R. M. Housley, and E. H. Cirlin, Surf. Sci. 124, 407(1983).

10 M. J. Pellin, W. Husinsky, W. F. Calaway, J. W. Burnett, E. L. Schweitzer, C. E. Young, B. Jørgensen and D. M. Gruen, submitted to J. Vac. Sci. Tech..

11. M. J. Pellin, C. E. Young, W. F. Calaway, J. W. Burnett, B. Jørgensen, E. L. Schweitzer, and D. M. Gruen, Nucl. Instru. Meth. B18, 446(1987).

12. C. E. Young, M. J. Pellin, W. F. Calaway, B. Jørgensen, E. L. Schweitzer, and D. M. Gruen, Inst. Phys. Conf. Ser. 84, 163(1987).

13. M. J. Pellin, C. E. Young, W. F. Calaway, and D. M. Gruen, Nucl. Instru. Meth. B13, 653(1986).

14. H. Tochihara, G. Rocker, R. M. Martin, H. Metiu, and J. T. Yates, Jr. , submitted to Surf. Sci..

15. K. Christmann, G. Ertl, and H. J. Shimizu, J. Catal. 61, 397(1980).

16. H. J. Shimizu, G. Ertl, and K. Christmann, J. Catal. 61, 412(1980). 
17. J. C. Vickermann, K. Christmann and G. Ertl, Surf. Sci. 120, 1.

18. J. C. Vickermann, K. Christmann, G. Ertl, P. Heimann, F. J. Himpsel, and D. E. Eastman, Surf. Sci. 134, 367(1983).

19. J. E. Houston, C. H. F. Peden, D. S. Blair and D. W. Goodman, Surf. Sci. 167, 367(1986).

20. J. T. Yates, Jr., C. H. F. Peden and D. W. Goodman, J. Catal. 24, 576(1985).

21. M.W. Roberts and C. S. McKee,The Chemistry of the Metal Cas Interface, Clarendon Press, Oxford, 1978,p. 154-158, 192, 193.

22. L. C. Feldman and J. W. Mayer, Fundamentals of Surface and Thin Film Analysis, North-Holland, New York, 1986.

23. I. Masuami, et al. , Institute of Plasma Physics Report of Nagoya University, Japan, IPRJ-AM14.

24 J. P. Biersack, Nucl. Inst. Meth. B27 21(1987).

25. A. B. DeWald, J. N. Lavidson, A. R. Krauss, and D. M. Gruen, J. Nucl. Mater. $\underline{111 \& 112}, 448(1982)$.

26. A. R. Krauss, D. M. Gruen, and A. B. DeWald, J. Nucl. Mater. $\underline{121,398(1984)}$

\section{Figure Captions}

Figure 1. A plot of the TRIM calculation of the first and second layer contributions to the total sputtering yield for $\mathrm{Ru}$ as a function of primary ion kinetic energy. Note that for primary ion energies of greater than $1-2 \mathrm{keV}$, the layer contributions to the depth of origin are nearly independent of the energy.

Figure 2. The SARISA apparatus.

Figure 3. A plot of the $\mathrm{Cu} / \mathrm{Ru}$ sputtering yield ratio, $\mathrm{S}_{\mathrm{Cu}} / \mathrm{SR}_{\mathrm{Ru}}$, versus $\mathrm{Cu}$ coverage in monolayers for both the experiment and the TRIM calculations. For both the experiment and the calculation, a $3.6 \mathrm{keV} \mathrm{Ar}{ }^{+}$beam was used. 


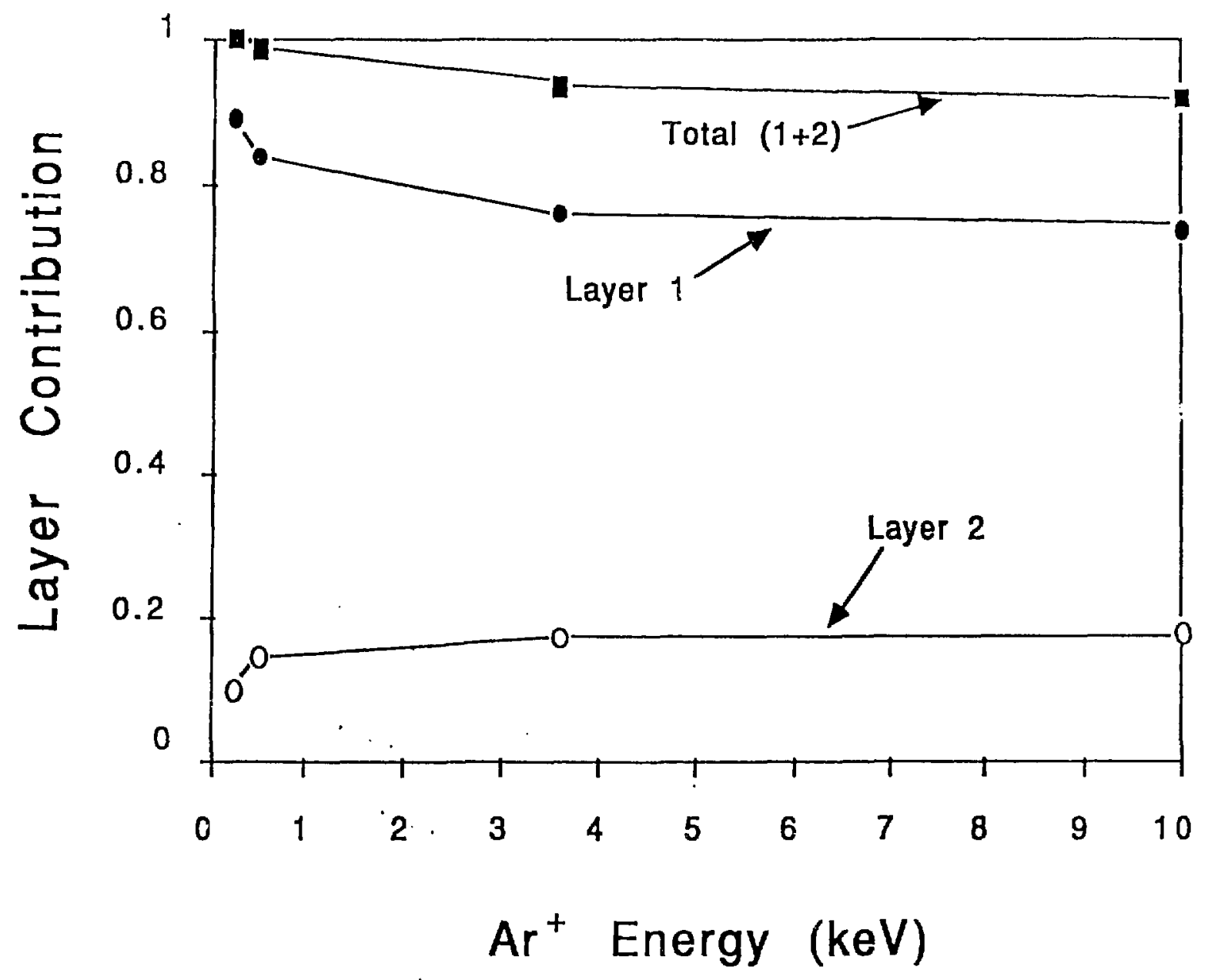




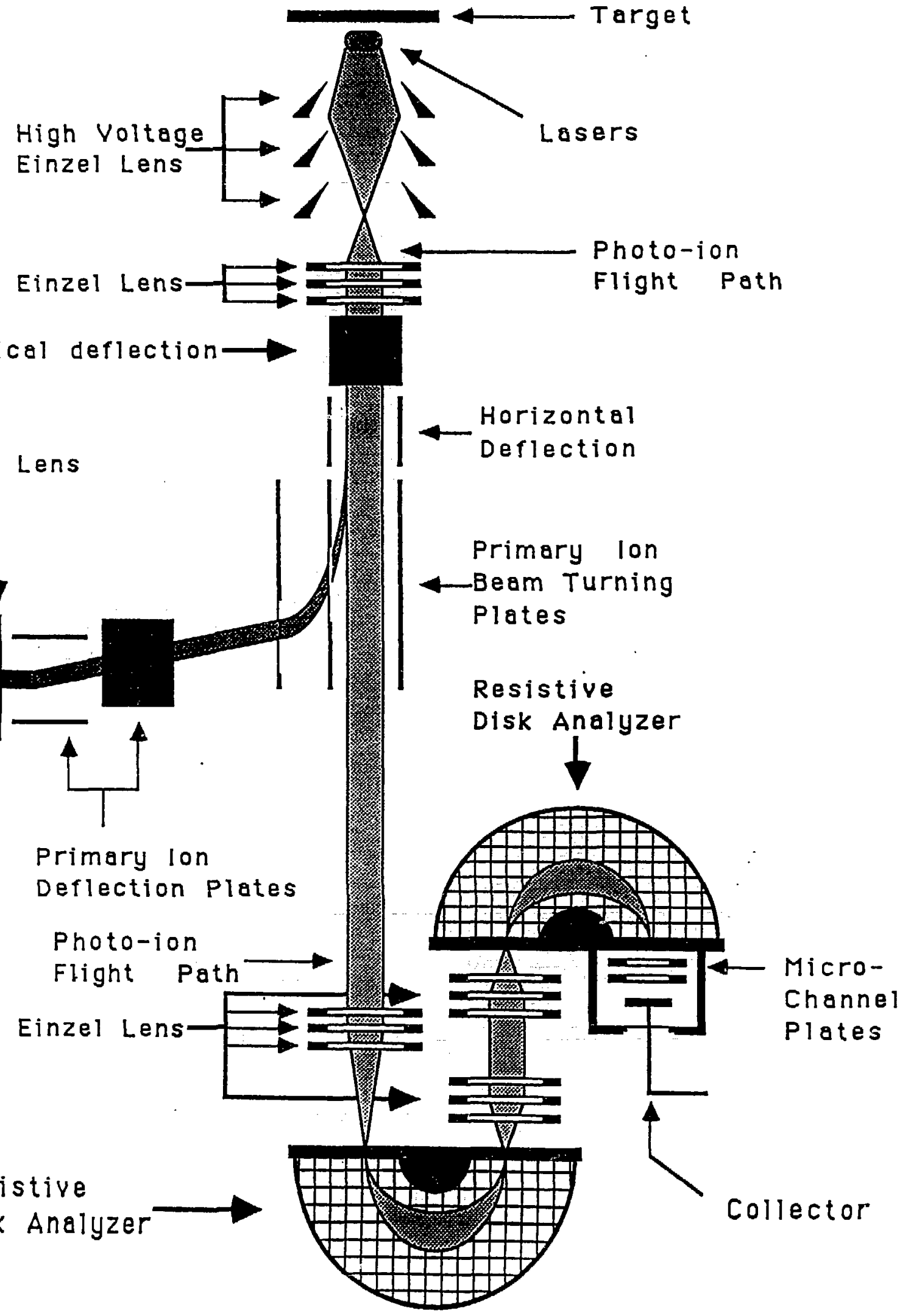

Figure 2. The SARISA apparatus. 


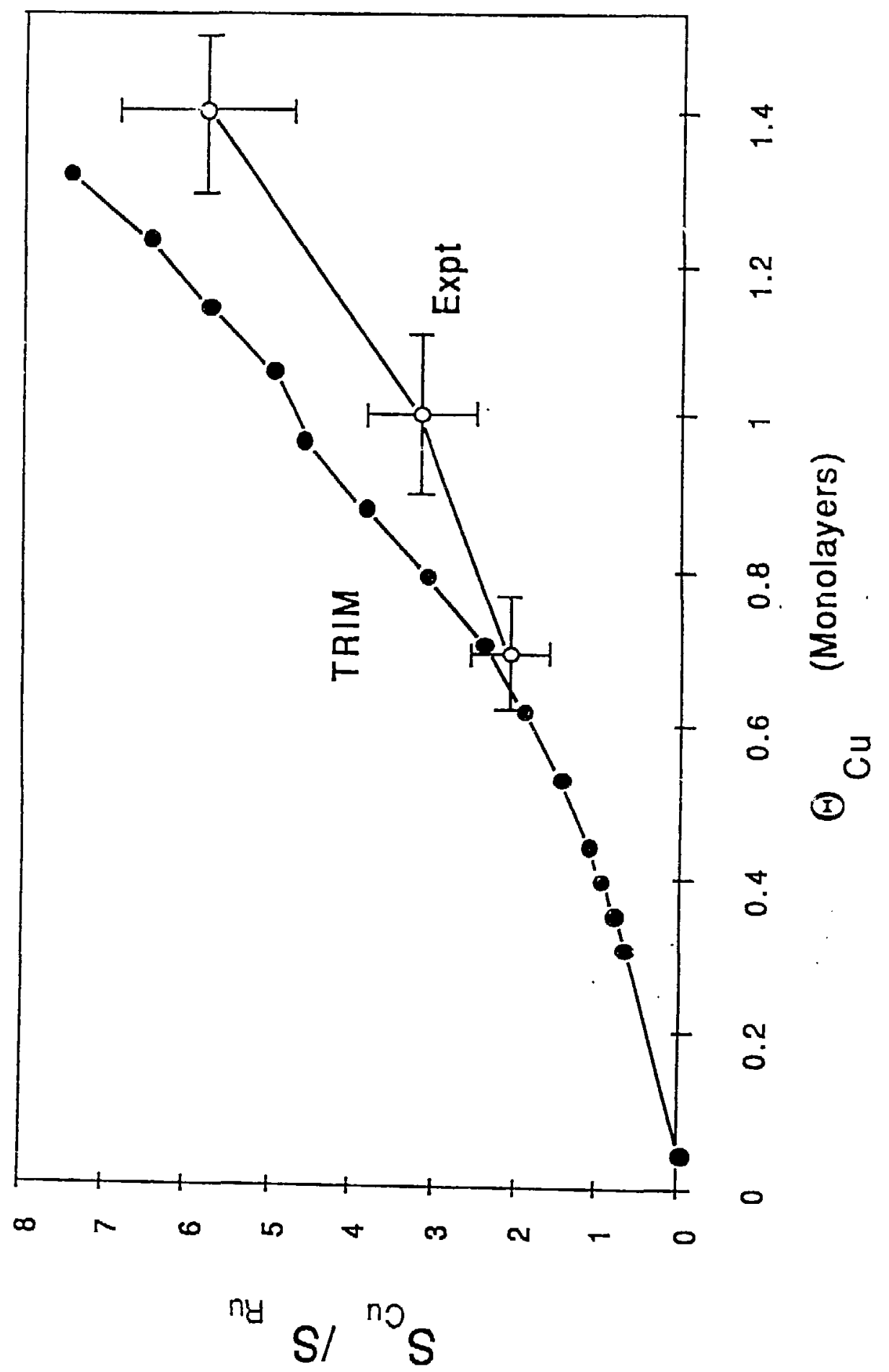

